\title{
Serum levels of 25(OH)-vitamin D and adipokine's profile in obese children and adolescents
}

\author{
Andra Caragheorgheopol, Iuliana Gherlan, Adriana Padure, \\ Suzana Vladoiu, F. Alexiu, Sorina Schipor
}

National Institute of Endocrinology “C.I.Parhon”, Bucharest, Romania

\section{Background}

There is an increasing body of evidences regarding hypovitaminosis D in children and adolescents. Low levels of 25-OH Vitamin D is associated with insulin resistance in adults. Recent in vitro studies have suggested that vitamin $\mathrm{D}$ may play a role in the regulation of adiponectin, leptin and resistin; since all these adipokines are related to insulin sensitivity modulation, they might represent a link between vitamin D status and insulin resistance.

\section{Objective}

To identify possible correlations between $25(\mathrm{OH})$-vitamin D serum levels and adipokine's profile in obese children and adolescents.

\section{Patients and method}

We evaluated 25-OH Vitamin D, insulin, adiponectin, leptin, resistin and HOMA index in 46 obese children and adolescents (age $14.3 \pm 2.2$ years) and in $\mathbf{3 0}$ age-matched healthy non-obese children (control group). 25-OH Vitamin D was measured by chemiluminiscence (Liaison DiaSorin), total adiponectin, leptin and resistin by Elisa (Quantikine, R\&D Systems), fasting insulin by RIA, and insulin resistance index calculated by homeostasis model assessment (HOMA). Vitamin D reference range was defined in accord with The Endocrine Society's Clinical Guidelines: deficiency $<20 \mathrm{ng} / \mathrm{ml}$, insufficiency $20-30 \mathrm{ng} / \mathrm{ml}$.

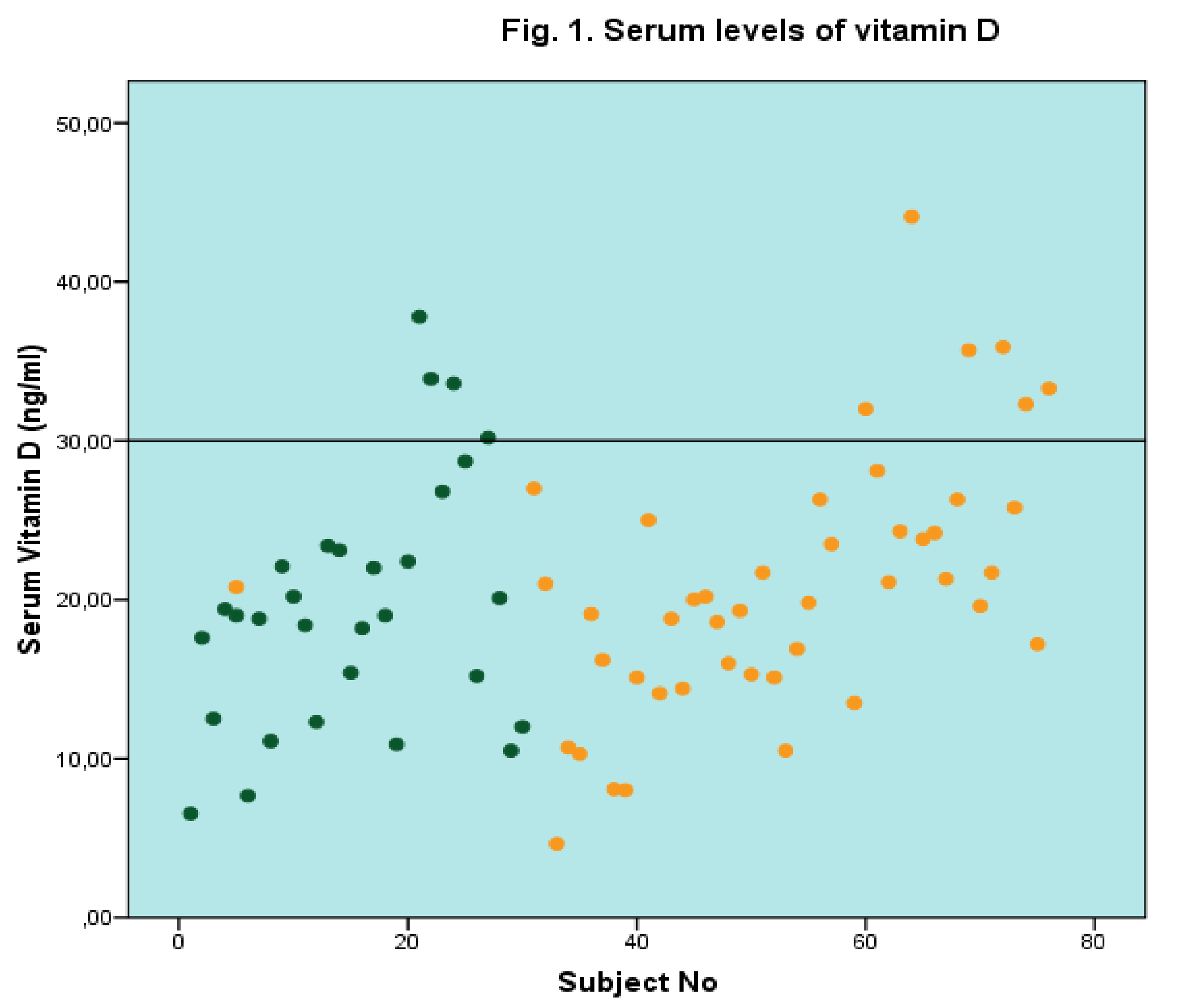

Results

85.5\% of subjects were vitamin D insufficient (serum vitamin D $<30 \mathrm{ng} / \mathrm{ml}$, Fig 1). From these, $87 \%$ were in the obese group and $83.3 \%$ in the control group. The plasmatic levels of $25(\mathrm{OH})$ vitamin D do not differ between groups (Fig 5).

The adiponectin levels were significantly lower (Fig 2), whereas leptin (Fig 3) and resistin have significantly higher values in the obese group compared to the control group.

\begin{tabular}{|c|c|c|c|}
\hline Parameter & $\begin{array}{l}\text { Obese Group } \\
\quad(\mathrm{n}=46)\end{array}$ & $\begin{array}{l}\text { Control Group } \\
(\mathrm{n}=\mathbf{3 0})\end{array}$ & $\mathbf{P}$ \\
\hline $\begin{array}{l}\text { Insulinemia } \\
\text { (uIJI/mI) }\end{array}$ & $24.04 \pm 13.37$ & $17.47 \pm 6.39$ & 0.011 \\
\hline HOMA -index & $4.69 \pm 2.79$ & $3.51 \pm 1.44$ & 0.033 \\
\hline Adiponectin ( $(\mu \mathrm{g} / \mathrm{dl})$ & $6.74 \pm 3.17$ & $12.54 \pm 8.13$ & $<0.001$ \\
\hline Leptin (ng/ml) & $35.37 \pm 24.02$ & $9.01 \pm 7.11$ & $<0.001$ \\
\hline Resistin (ng/ml) & $9.01 \pm 2.60$ & $7.23 \pm 1.95$ & 0.002 \\
\hline Vitamin D (ng/ml) & $20.79 \pm 7.99$ & $19.63 \pm 7.83$ & 0.532 \\
\hline
\end{tabular}

25(OH)-vitamin $\mathrm{D}$ was negatively correlated to fasting insulinemia $(\mathrm{r}=-0.324, \mathrm{p}=0.036)$ and to plasmatic levels of leptin $(\mathrm{r}=-0.363, \mathrm{p}=0.013)$; in multivariate regression analysis the only parameter that influenced vitamin D status in obese children was leptin.
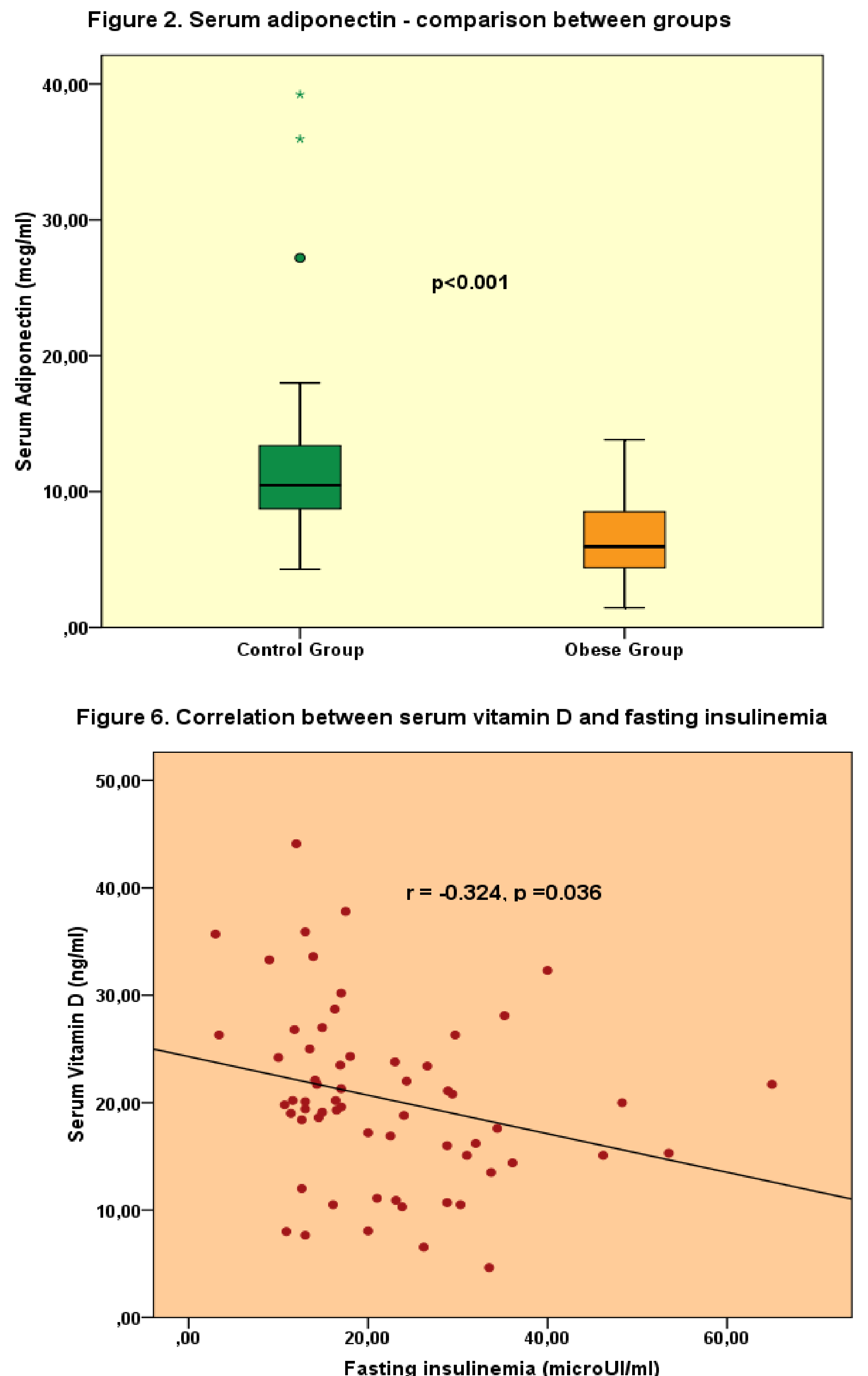
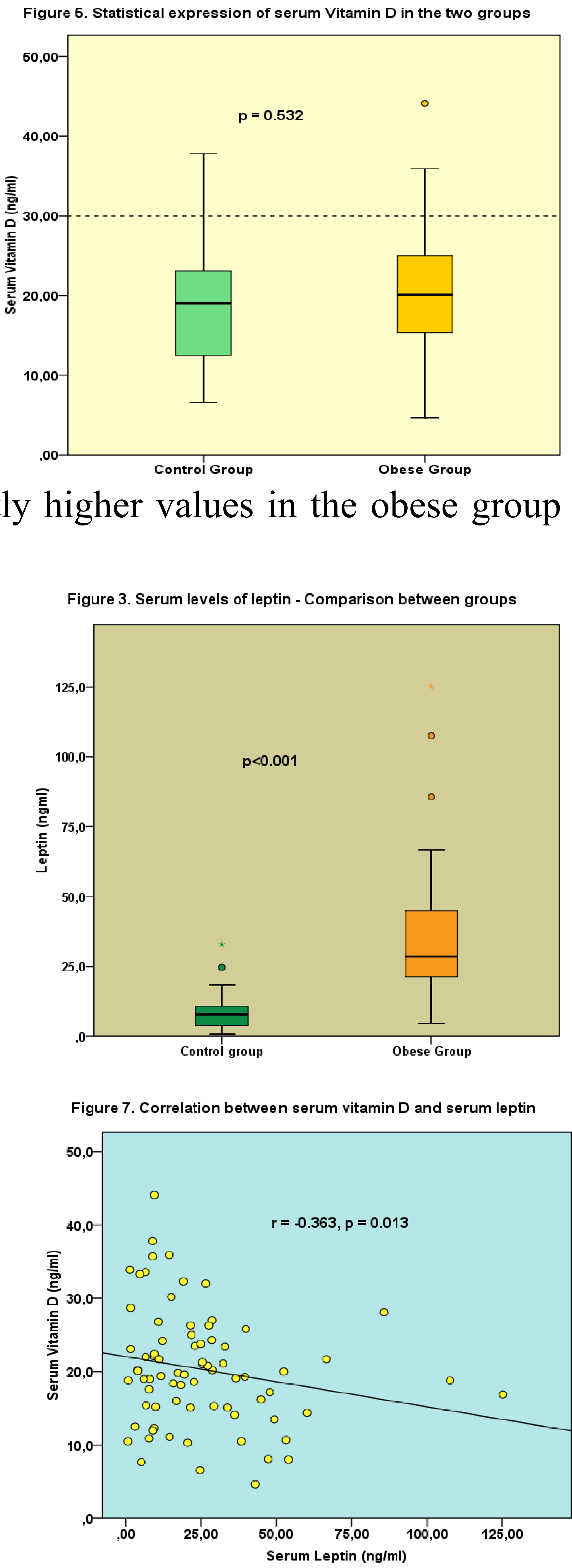

We found no correlation between plasmatic levels of $25(\mathrm{OH})$-vitamin D and adiponectin or 25(OH)-vitamin D and resistin, respectively.

Conclusion We found an insufficiency of vitamin D in a large majority of selected Romanian children. Vitamin D deficit in obese children is related to hyperinsulinemia, their association being explained by a parallel variation with plasmatic levels of leptin.

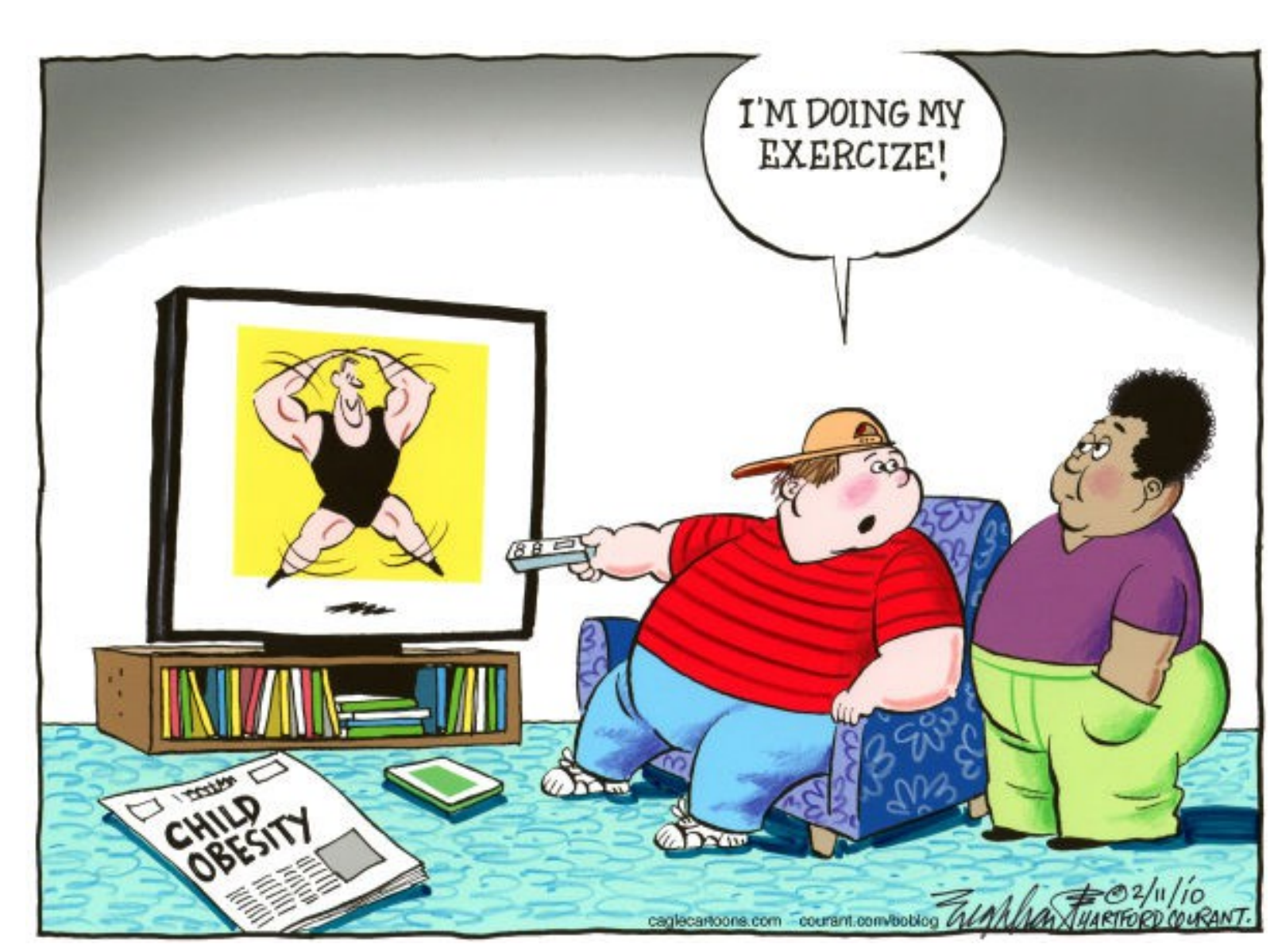

